\title{
Effects of Temperature on Events in the Infection Cycle of Two Clonal Lineages of Phytophthora infestans Causing Late Blight on Tomato and Potato in Brazil
}

\author{
José Marcelo N. Maziero, Luiz A. Maffia, and Eduardo S. G. Mizubuti, Departamento de Fitopatologia - Univer- \\ sidade Federal de Viçosa, 36570-000 Viçosa-MG, Brazil
}

\begin{abstract}
Maziero, J. M. N., Maffia, L. A., and Mizubuti, E. S. G. 2009. Effects of temperature on events in the infection cycle of two clonal lineages of Phytophthora infestans causing late blight on tomato and potato in Brazil. Plant Dis. 93:459-466.

In Brazil, US-1 and BR-1 clonal lineages of Phytophthora infestans are widely distributed throughout the major growing areas of tomato and potato, respectively. Quantitative information regarding the effects of temperature $\left(10,15,22\right.$, and $\left.27^{\circ} \mathrm{C}\right)$ on direct and indirect sporangia germination, incubation period (IP), latent period (LP), lesion area (LA), and sporulation (SP), as well as combined temperature and leaf wetness duration periods $(6,12,18$, and $24 \mathrm{~h})$ on the number of lesions (NL) was obtained under controlled conditions on either detached leaflets or whole plants. The percentage of indirect germination was higher for BR-1 isolates than for US1. The percentage of direct germination was higher for US-1 than for BR-1. The shortest IP and LP were recorded at $22^{\circ} \mathrm{C}$ for both lineages: $69.3 \mathrm{~h}$ and $93.3 \mathrm{~h}$ for US-1 isolates on detached tomato leaflets, and $44.0 \mathrm{~h}$ and $68 \mathrm{~h}$ for BR-1 isolates on detached potato leaflets, respectively. US-1 isolates did not sporulate at $10^{\circ} \mathrm{C}$, and BR-1 isolates did not sporulate at $27^{\circ} \mathrm{C}$. Isolates of both lineages induced the largest LA at $22^{\circ} \mathrm{C}$. The NL was highest at $15^{\circ} \mathrm{C}$ for US- 1 isolates on whole tomato plants, and at $10^{\circ} \mathrm{C}$ for BR-1 isolates on whole potato plants. The differential effects of temperature on US-1 and BR-1 suggest that current decision support systems initially developed for controlling US-1 in Brazil may now be inaccurate for controlling BR-1, and management strategies should be properly validated before being used.
\end{abstract}

In Brazil, tomatoes (Solanum lycopersicum L. = Lycopersicon esculentum Mill.) are widely planted throughout the country, but at relatively low altitudes. In contrast, potatoes (Solanum tuberosum L.) are produced in areas of high altitudes (above 800 $\mathrm{m}$ ), and confined mostly to the south and southeast regions. In each production region, several tomato and potato crops are continuously grown, with more than one planting per year. Although the same field is not cultivated with either tomato or potato successively, new tomato plantings are sometimes established near old tomato fields, and the same can occur for potatoes. The severity of late blight epidemics, caused by Phytophthora infestans, the most destructive disease of both host crops, has been observed to vary depending on planting date. Late blight epidemics develop with higher progress rates during the summer (rainy season) than during the winter (dry season) (24).

Corresponding author: E. S. G. Mizubuti E-mail: mizubuti@ufv.br

Current address of J. M. N. Maziero: Delegacia Federal de Agricultura, CEP 79002-970, Campo Grande, MS.

Accepted for publication 10 December 2008.

doi:10.1094/PDIS-93-5-0459

(c) 2009 The American Phytopathological Society
Late blight epidemics are favored by moderate temperatures and high humidity (12). Temperature and leaf wetness duration periods affect different stages of the life cycle of $P$. infestans. Temperature affects sporulation $(1,29)$, infection, lesion expansion rate (15), inoculum survival (23), and sporangia germination (4). Sporangia germination is a temperature-driven process: below $15^{\circ} \mathrm{C}$, zoospores are formed (indirect germination); whereas above $18^{\circ} \mathrm{C}$, sporangia preferentially form germ tubes (4), a process referred to as direct germination. Once inside the plant, host colonization and pathogen sporulation are also affected by temperature, and more sporangia form optimally in the range of 18 to $22^{\circ} \mathrm{C}$ (12). Temperature also affects the survival of both sporangia $(5,23)$ and oospores $(6,21,33)$. Water, either as vapor or liquid, plays an important role on late blight development because it affects germination, sporulation, and inoculum survival. Prolonged periods with leaf wetness and/or high relative humidity are required for sporangia germination and infection establishment (12). Humidity can also affect sporulation (14) and sporangia survival (23). Abundant sporulation and extended sporangia viability also occur under high humidity conditions.

Under favorable environmental conditions, late blight outbreaks are likely to occur and fungicides are intensively applied to both tomato and potato crops in
Brazil. Depending on weather conditions, more than 15 fungicide sprays per season can be applied to each crop. Although no study has been designed to quantify fungicide usage, growers now report that more applications are being required to achieve efficient disease suppression. Similar situations have been reported elsewhere $(11,17)$ which could be associated with changes in the pathogen population and the spread of more aggressive genotypes (7).

In Brazil, there are two clonal populations of $P$. infestans: a tomato adapted clonal lineage, US-1, and a potato adapted lineage, BR-1 (27). The US-1 clonal lineage, which comprises isolates of the A1 mating type, is considered to be an old population of $P$. infestans that is distributed worldwide (9). BR-1 is a new lineage first reported in Brazil in 1986 (2) and is comprised of isolates of the A2 mating type (9). Brazilian populations of $P$. infestans are host-specific: US-1 isolates cause late blight on tomato, whereas BR-1 isolates are associated with potato. Even though isolates of these two clonal lineages can infect both hosts, they are more aggressive to the host with which they are predominantly associated (30).

Host specificity and putative differences in ecological requirements of $P$. infestans lineages necessitate differential late blight management strategies, according to hostclimate interaction. As previously mentioned, in Brazil, potatoes and tomatoes are cultivated in different climatic zones. Considering the differences in the planting areas, the strong association of a clonal lineage with either potato or tomato could be, at least in part, due to differences in ecological requirements of isolates of either lineage. Furthermore, there is strong evidence that the new populations of $P$. infestans have different ecological requirements than the old US-1 lineage. For example, sporangia of isolates of the US-7 and US-8 clonal lineages germinated faster at temperatures below $15^{\circ} \mathrm{C}$ when compared to US-1 isolates (25). Also, US-8 isolates apparently are more lowtemperature tolerant than US-1 (18).

There is no quantitative information on the effects of environmental factors on Brazilian isolates of $P$. infestans. Despite the importance of late blight epidemics on tomato and potato crops, no study has yet been conducted in Brazil to address the effects of temperature and leaf wetness duration in the infection cycle of $P$. in - 
festans. Most of the information currently used in Brazil is still based on data gathered on temperate climates and on isolates of the US-1 lineage. Thus, the objective of this study was to quantify the effects of (i) temperature on sporangia germination, incubation period, latent period, lesion area, and sporulation of isolates of the two clonal lineages of $P$. infestans, and (ii) the combination of temperature-leaf wetness duration on the number of lesions incited by isolates of these lineages.

\section{MATERIALS AND METHODS}

Temperature effects on sporangia germination. $P$. infestans isolates used in the experiments were collected in different geographical regions of Brazil (Table 1). The genetic structure of the Brazilian population of $P$. infestans has previously been shown to be strictly clonal with negligible differences at the molecular level among isolates of a lineage (27). The isolates were grown on rye B (3) on petri dishes kept at $18^{\circ} \mathrm{C}$ with $16 \mathrm{~h}$ of light and $8 \mathrm{~h}$ of dark. After a 14-day growing period, $10 \mathrm{ml}$ of sterile distilled water were added to each plate and sporangia were dislodged with a soft paintbrush. To keep isolates virulent, they were periodically inoculated on detached leaflets of susceptible (no $\mathrm{R}$ genes) tomato cv. Kada and potato $\mathrm{cv}$. Bintje. The tomato isolates were inoculated to tomato leaflets and the potato isolates to potato leaflets. A drop of $20 \mu \mathrm{l}$ of a suspension of $10^{4}$ sporangia/ml of each isolate was deposited on the abaxial side of a leaflet of the respective host. The inoculated leaflets were kept in moist chambers at $18^{\circ} \mathrm{C}, 24-\mathrm{h}$ light regime $(233.4$ $\mu \mathrm{mol} / \mathrm{s} / \mathrm{m}^{2}$ ). After 10 days, the lesions that developed were gently touched with a piece of moistened sterile filter paper $(1 \times$ $1 \mathrm{~cm})$ to capture sporangia, and the filter paper with sporangia was imprinted onto the surface of water agar $(1.5 \%)$ in petri dishes. Three equally distant prints in a triangle shape were made per dish. The dishes were kept at $10,15,22$, or $27^{\circ} \mathrm{C}$. After $12 \mathrm{~h}$, a portion of approximately 4 $\mathrm{cm}^{2}$ of the agar medium containing sporangia was cut from each dish and transferred, the surface containing sporangia facing up, to a glass slide. A drop of lactophenol was added and a coverslip covered

Table 1. Characteristics of the Brazilian US-1 and BR-1 isolates of Phytophthora infestans used in the experiments

\begin{tabular}{lclcccl}
\hline Isolate & $\begin{array}{c}\text { Clonal } \\
\text { lineage }\end{array}$ & $\begin{array}{l}\text { Host of } \\
\text { origin }\end{array}$ & $\begin{array}{c}\text { Mating } \\
\text { type }\end{array}$ & State & Region & $\begin{array}{l}\text { Metalaxyl } \\
\text { sensitivity }\end{array}$ \\
\hline Pib-4 & BR-1 & Potato & A2 & SC & S $^{\mathrm{c}}$ & Intermediate $^{\mathrm{a}}$ \\
Pib-193 & BR-1 & Potato & A2 & MG & SE & Resistant \\
Pib-198 & BR-1 & Potato & A2 & MG & SE & Resistant \\
Pib-214 & US-1 & Tomato & A1 & SC & S & Sensitive \\
Pib-239 & US-1 & Tomato & A1 & MG & SE & Sensitive \\
Pib-256 & US-1 & Tomato & A1 & SP & SE & Sensitive \\
\hline
\end{tabular}

${ }^{a}$ Clonal lineage and metalaxyl sensitivity of each isolate was determined as described elsewhere (27).

b SC, MG, and SP = Santa Catarina, Minas Gerais, and São Paulo states, respectively.

${ }^{\mathrm{c}} \mathrm{S}$ and $\mathrm{SE}=$ south and southeast Brazilian regions, respectively. greenhouse were placed in $11 \times 11 \times 4 \mathrm{~cm}$ plastic boxes. Tomato leaflets were inoculated with isolates from tomato plants and potato leaflets with isolates from potato plants. Each box was lined with sterile paper towels wetted with sterile distilled water and contained three leaflets of either tomato or potato. Each leaflet was inoculated by placing a $20-\mu \mathrm{l}$ drop of a $3 \times 10^{4}$ sporangia/ml suspension in the central part on the abaxial side. After inoculation, the boxes were covered and transferred to incubators at $10,15,22$, or $27^{\circ} \mathrm{C}$.

The following variables were assessed:

Incubation period (IP), defined as the time (h) between inoculation and symptom appearance, was determined by visually observing the inoculated leaflets at 36,44 , $52,60,68,76,84,92,100,108$, and $116 \mathrm{~h}$ after inoculation (hai). The IP was considered completed when symptoms (tiny necrotic spots) were observed on at least two of the three inoculated leaflets in each box.

Latent period $(L P)$, defined as the time (h) between inoculation and formation of sporangiophores with or without sporangia, was determined by inspecting each lesion under a stereoscope at the same time intervals described for IP. The LP was considered completed when sporangiophores were observed on at least two of the three inoculated leaflets in each box. This operational definition of LP was chosen to speed the assessment time and allow evaluation of all experimental units within a shorter time interval.

Lesion area (LA) was measured daily from 36 hai until 180 hai, depending on the temperature in which leaflets were maintained. Lesions were photographed with a digital camera and the images were processed with the ImageTool software (http://ddsdx.uthscsa.edu/dig/itdesc.html).

Each image was visually inspected and the border of each lesion was manually delimited. The software measures lesion area $\left(\mathrm{cm}^{2}\right)$ based on the number of pixels inside the delimited polygon.

Sporulation $(S P)$. Two experiments using whole plants were established to quantify the effect of temperature on $P$. infestans sporulation. Fifteen leaflets of tomato 'Kada' or 15 of potato 'Bintje', 7 to 8 weeks old, were inoculated with a $50-\mu \mathrm{l}$ drop of $3 \times 10^{4}$ sporangia/ml suspension of each isolate of US-1 or BR-1, respectively. Immediately after inoculation, the plants were covered with plastic bags, as described above, and transferred to growth chambers at $10,15,22$, or $27^{\circ} \mathrm{C}$, with a 14 -h photoperiod. After 24 hai, the plastic bags were removed. To keep the lesions wet, plants were sprayed every $8 \mathrm{~h}$ with distilled water for 7 days. For the plants kept at $10^{\circ} \mathrm{C}$, the wetting procedure extended up to 10 days after inoculation. On the seventh or tenth day (for plants kept at $10^{\circ} \mathrm{C}$ ), the plants were sprayed with distilled water and covered with plastic bags to provide wet conditions and stimulate sporulation. 
Based on data collected on different sets of leaflets of tomato and potato plants, equations were generated to estimate lesion area by measuring length and width of 100 lesions and calculating the area of an ellipsis. To assess the "real" area of a lesion, an image was obtained with a digital camera and the lesion area was measured using the ImageTool software. Through regression analysis of the estimated area (ellipsis) versus real area (digital images), two equations were generated: Tomato lesion area $=-2.090+1.213$ length + 1.634 width $\left(R^{2}=0.85\right)$; and Potato lesion area $=-2.331+1.703$ length +1.117 width $\left(R^{2}=0.88\right)$.

In the experiment, length and width of 12 lesions per plant per treatment were measured and the areas were estimated using the proper equation. Lesions were then cut and transferred to test tubes with 5 $\mathrm{ml}$ of preservation solution $(2.5 \mathrm{ml}$ of distilled water and $2.5 \mathrm{ml}$ of $0.04 \mathrm{M}$ $\mathrm{CuSO}_{4} / 0.2 \mathrm{M}$ sodium acetate/acetic acid, $\mathrm{pH}$ 5.4). Tubes were vortexed for $20 \mathrm{~s}$ to dislodge sporangia. The plant tissue was removed, and the suspension was kept at $4^{\circ} \mathrm{C}$. Sporangia were counted using a hemacytometer. The number of sporangia per unit of lesion area was determined as previously described (25).

All experiments were conducted twice, each in a completely randomized design. Three replicates were used in the experiments to assess temperature effects on IP, LP, and LA. A plastic box with three leaflets comprised an experimental unit. For the SP experiment, there were 15 replicates; a pot with one plant comprised an experimental unit.

Statistical analyses. All data were analyzed with the SAS System version 8.0 (SAS Institute Inc., Cary, NC). The homogeneity of variances between experiments was tested using PROC MIXED, based on the difference of -2REML Log Likelihood values and the significance level calculated based on the chi-square distribution (20). Data of two experiments were pooled when the hypothesis of equal variances was not rejected.

To analyze the effect of temperature on sporangia germination, IP, LP, and SP, the treatment design was a nested-crossed factorial, and the mixed effects linear model used for the analyses of variance was: $Y_{i j k l}=\mu+\alpha_{i}+b_{j(i)}+\gamma_{k}+\alpha \gamma_{i k}+b c_{j k(i)}$ $+e_{i j k l}\left(\mu=\right.$ overall mean, $\alpha_{i}=$ fixed effect of clonal lineage, $b_{j(i)}=$ random effect of isolates nested within clonal lineages, $\gamma_{k}=$ fixed effect of temperature, $\alpha \gamma_{i k}=$ interaction term of clonal lineage and temperature [fixed], $b c_{j k(i)}=$ interaction term of isolates nested within clonal lineages and temperature [random], and $e_{i j k l}=$ random experimental error) (19). Similar models were fit to analyze the effect of temperature and leaf wetness on the number of lesions as well as the effect of temperature and time on LA.

\section{RESULTS}

Temperature effects on sporangia germination. Data were pooled for analysis because variances of both experiments did not differ $(P=0.053)$. The average clonal lineage effect was estimated. There was significant clonal lineage $\times$ temperature interaction when analyzing direct $(F=$ 23.9; $P<0.0001)$ and indirect germination $(F=27.3 ; P<0.0001)$. Temperature had a differential effect on sporangia germination depending on the clonal lineage. For isolates of both lineages, the indirect germination was highest at $10^{\circ} \mathrm{C}$ (Fig. 1A). For both US-1 and BR-1, indirect germination decreased as temperature increased, but the indirect germination of US-1 was lower than that of BR-1 isolates. At $22^{\circ} \mathrm{C}$, sporangia of US-1 did not germinate indirectly, while the germination of BR-1 was $0.57 \%$. At $27^{\circ} \mathrm{C}$, indirect germination of isolates of both lineages was minimal (Fig. 1A). For both lineages, highest direct germination was at $22^{\circ} \mathrm{C}$ (Fig. 1B). There was no direct germination at $10^{\circ} \mathrm{C}$ for either clonal lineage. Direct germination levels of US-1 isolates were higher than those of the BR-1 isolates at 15,22 , and $27^{\circ} \mathrm{C}$ (Fig. 1B). Direct germination of BR-1 isolates was low at 15 and $27^{\circ} \mathrm{C}$ (Fig. 1B).

Number of lesions caused by isolates of US-1 and BR-1 clonal lineages. Tem-
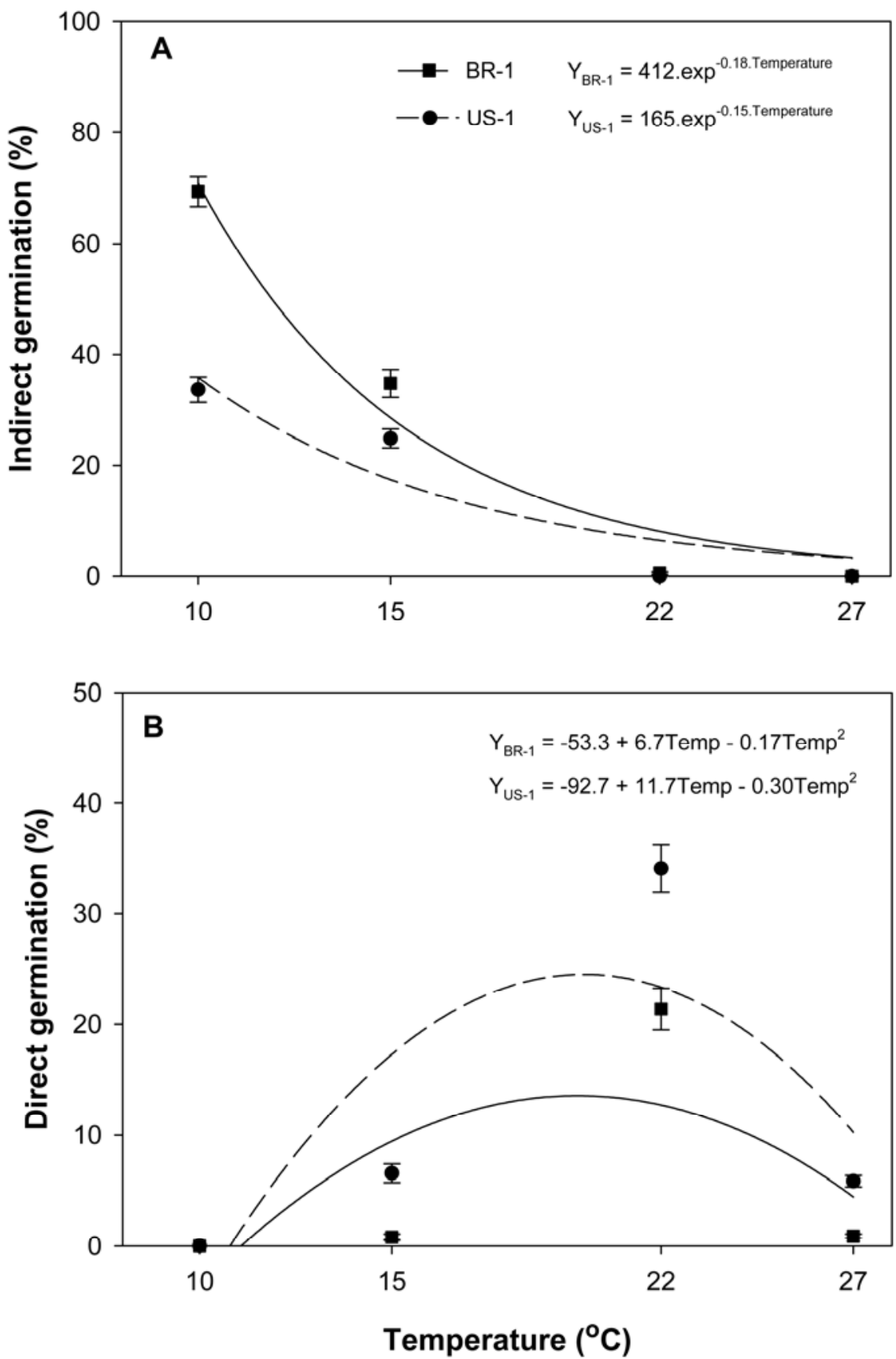

Fig. 1. Indirect (A) and direct (B) germination of sporangia of Phytophthora infestans isolates of BR-1 and US-1 clonal lineages at different temperatures. Data from two experiments were pooled. Error bars represent the standard deviation. All regression models were significant $(P=0.05)$. 
perature and leaf wetness duration differentially affected the isolates of the two lineages. The US-1 isolates produced almost no lesions at $10^{\circ} \mathrm{C}$, whereas for BR-1 the maximum number of lesions occurred at $10^{\circ} \mathrm{C}$ (Fig. 2). For US-1 isolates, the maximum number of lesions occurred at $15^{\circ} \mathrm{C}$, with slightly fewer lesions at $22^{\circ} \mathrm{C}$, and still some lesions at $27^{\circ} \mathrm{C}$. BR-1 isolates produced no lesions at $27^{\circ} \mathrm{C}$. In general (except at $27^{\circ} \mathrm{C}$ ), US-1 isolates produced fewer lesions than BR-1 isolates. For isolates of both lineages, more lesions were produced when the duration of leaf wetness lasted 18 or $24 \mathrm{~h}$.

Temperature effects on incubation period, latent period, lesion area, and sporulation. For all variables assessed, data from the two experiments were pooled for analysis after testing for homocedasticity.

Incubation period. The interaction between clonal lineage and temperature was significant $(P<0.001)$ (Table 2$)$. Shortest IP for both lineages occurred at $22^{\circ} \mathrm{C}$, and was $69.3 \mathrm{~h}$ for US-1 in both experiments (Fig. 3A), and 44.0 and $49.3 \mathrm{~h}$ for BR-1 in experiments 1 and 2 , respectively. The longest IP times were at 10 and $27^{\circ} \mathrm{C}$, for US-1 and BR-1, respectively (Fig. 3A).

The variance component for isolates within clonal lineages was low (0.89) compared to the variance component of the residual (44.3) (Table 2). The latter estimates the amount of variance that is left over after the variance due to isolates within clonal lineages and the interaction temperature $\times$ isolates nested in clonal lineages have been explained. Thus, the variation between isolates was not high and the differences between clonal lineages were more evident $(F=214.4 ; P<$ 0.001) (Table 2).

Latent period. The interaction between clonal lineages and temperature was significant $(P<0.001)$ (Table 2$)$. Thus, temperature differentially affected LP of the clonal lineages, but for all temperatures, US-1 isolates took longer to develop than did BR-1 isolates. The general trend for isolates of both lineages was a reduction of LP with increasing temperatures up to $22^{\circ} \mathrm{C}$. Between 22 and $27^{\circ} \mathrm{C}, \mathrm{LP}$ tended to increase (Fig. 3B). No sporangiophores were produced by US- 1 isolates at $10^{\circ} \mathrm{C}$ or by BR-1 isolates at $27^{\circ} \mathrm{C}$ (Fig. 3B). Thus, in both cases the LP was not recorded. Shortest $\mathrm{LP}$ values were recorded at $22^{\circ} \mathrm{C}$ for isolates of both lineages in both experiments. At $22^{\circ} \mathrm{C}$, LP values for US- 1 in experiments 1 and 2 were 93.3 and 106.0 $\mathrm{h}$, respectively, and for BR-1 in experiments 1 and 2 were 68.0 and $76.7 \mathrm{~h}$, respectively (Fig. 3B). Most variability was due to the residual term (66.6); variation among isolates within clonal lineages was low, 2.7 (Table 2).

Lesion area. In general, at higher temperatures more lesions were incited by the US- 1 isolates than by the BR-1 isolates $(P$ $=0.0006)$. At $10^{\circ} \mathrm{C}$, the US- 1 isolates induced no lesions, whereas the BR-1 isolates did (Fig. 4). Conversely, at $27^{\circ} \mathrm{C}$, US-1 induced lesions, whereas no BR-1 isolates did. For US-1, lesion growth rates
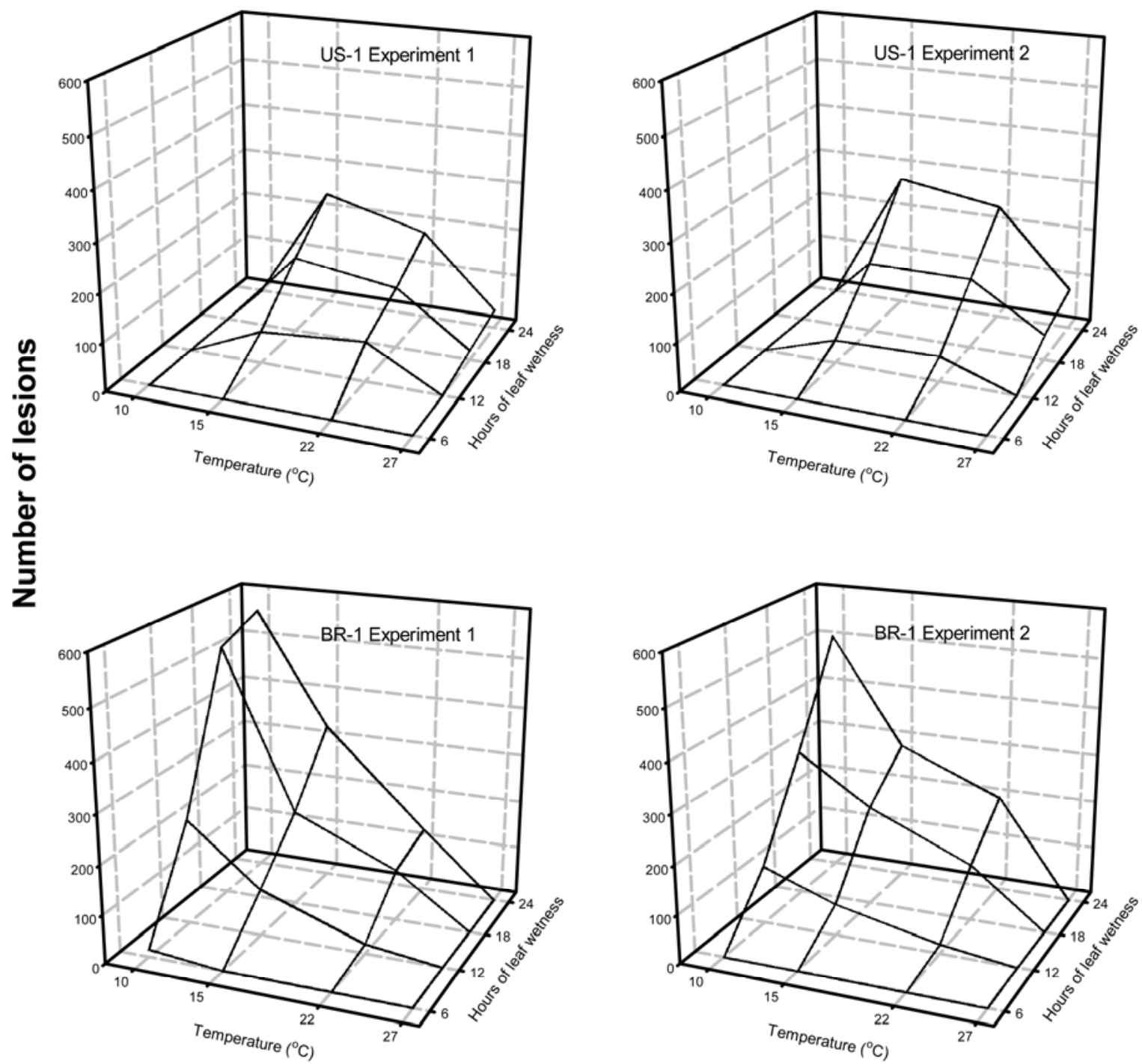

Fig. 2. Number of lesions caused by isolates of US-1 and BR-1 clonal lineages of Phytophthora infestans in plants that were kept in different combinations of temperature and leaf wetness duration after inoculation. Values are averages from the two experiments. Isolates of US-1 or BR-1 were inoculated in tomato or potato plants, respectively. 
increased with temperature from 15 through $27^{\circ} \mathrm{C}$. For BR-1 isolates, lesion growth rates increased with temperature from 10 through $22^{\circ} \mathrm{C}$. Variation among isolates within clonal lineages was low, 0.17 (Table 2).

Sporulation. Temperature differentially affected sporulation of the clonal lineages $(P=0.0260)$, and the maximum sporulation of the US-1 isolates occurred at slightly higher temperatures than that of the BR-1 isolates. Maximum sporangia production of US-1 isolates was at $22^{\circ} \mathrm{C}$, and they did not sporulate at $10^{\circ} \mathrm{C}$ (Fig. 3C). BR-1 isolates sporulated most at either 15 or $22^{\circ} \mathrm{C}$, and they did not sporulate at $27^{\circ} \mathrm{C}$ (Fig. $3 \mathrm{C}$ ).

\section{DISCUSSION}

Important events during the infection cycle of the Brazilian clonal lineages of $P$. infestans were differentially affected by temperature. In general, the optimum temperature for BR-1 isolates to develop faster, to cause more lesions, and to produce more sporangia were lower than the optimum for the US-1 isolates. Indirect germination, which is favored by low temperatures $(4,22)$, was higher for BR-1 isolates. Direct germination, which is favored by temperatures above $20^{\circ} \mathrm{C}$, was higher for US-1 isolates. Effects of temperature on sporangia germination are well known (4). Even though detailed information on how temperature affects genes involved in zoospore formation has been gathered $(31,32)$, isolates of the new and old lineages of $P$. infestans have not yet been compared regarding differential response to temperature at the gene level. Differences in temperature responses between US- 1 and BR-1 lineages could be related to potentially different alleles/genes present in isolates of these lineages and/or to the variable amount of expression of simi- lar genes. At this point, there are no data to support this claim, and further research to assess differences in gene expression of new versus old lineages of $P$. infestans is needed.

The low temperature requirement for high germination levels of BR-1 isolates could restrict epidemic development in subtropical/tropical areas. However, this seems not to be the case for late blight epidemics on potatoes in Brazil that are caused by BR-1, as production areas are located at higher altitudes where night temperatures are suitable for sporangia germination. At nighttime, the combination of mild temperatures and high humidity creates favorable microclimatic conditions for sporangia germination. Historical monthly average temperatures from April to October, the major potato growing season, in the producing areas where BR-1 isolates were collected, ranged from 9.5 to $21^{\circ} \mathrm{C}$. Therefore, periods with favorable temperatures do occur and epidemic development follows.

The combined effects of temperature and leaf wetness duration periods on the number of lesions were largely influenced by temperature. Extending the leaf wetness period to $24 \mathrm{~h}$ did not compensate for the effects of limiting temperatures. At $27^{\circ} \mathrm{C}$ and $24 \mathrm{~h}$ of leaf wetness duration, there were no lesions on potato leaflets inoculated with BR-1 isolates, probably because no sporangia germinated at $27^{\circ} \mathrm{C}$. US- 1 isolates caused no lesions at $10^{\circ} \mathrm{C}$, in both hosts, even when the leaflets remained wet for $24 \mathrm{~h}$, despite the fact that sporangia germinated at this temperature. Most likely, the low temperature was the major factor that limited lesion formation. It is known that optimum temperatures for late blight epidemics are between 16 and $23^{\circ} \mathrm{C}$ (12), and there is practically no epidemic at $7^{\circ} \mathrm{C}(16)$ or above $28^{\circ} \mathrm{C}$ (28). Develop- ment of lesions by BR-1 and US-1 at 10 and $27^{\circ} \mathrm{C}$, respectively, reinforces the idea that BR-1 isolates are favored by low temperatures and US-1 isolates by higher temperatures.

The effects of temperature on IP, LP, and LA cannot be properly explained at this time due to the lack of detailed data on how pathogen mycelium inside host tissues is affected. Lesion area can be influenced by the intensity of pathogen colonization in the host. The amount of pathogen hyphae of an isolate putatively of the US-1 lineage in potato leaflets was lower at $13^{\circ} \mathrm{C}$ than at $17^{\circ} \mathrm{C}(13)$. To date, there is no report on mycelial growth of isolates of the new lineages inside host tissues. The absence of pathogen structures on lesions of BR-1 isolates at $27^{\circ} \mathrm{C}$ could be attributed to unfavorable temperature for growth and/or sporulation. After 15 days at $10^{\circ} \mathrm{C}$ or 8 days at $27^{\circ} \mathrm{C}$, US- 1 or BR-1 isolates, respectively, did not complete the $\mathrm{LP}$ in the inoculated leaflets. However, when the leaflets were transferred to $20^{\circ} \mathrm{C}$, the lesions started to produce sporangia after 12 $\mathrm{h}$ (data not shown). This suggests that the pathogen can remain viable inside the host under unfavorable conditions; as soon as the conditions become favorable, it may quickly return to an active state.

The continuous moist conditions in which the inoculated leaflets were kept allowed sporulation over a wide range of temperatures. High numbers of sporangia/unit area were recorded at 15 and $22^{\circ} \mathrm{C}$. This agrees with the optimum temperature range reported previously in which plenty of sporangia formed from 18 to $22^{\circ} \mathrm{C}$ under high relative humidity $(1,25)$. Observing that there was no sporulation of US- 1 isolates at $10^{\circ} \mathrm{C}$ or of BR-1 isolates at $27^{\circ} \mathrm{C}$ reinforces the findings of the experiments with detached leaflets in which no lesion developed at 10 or $27^{\circ} \mathrm{C}$

Table 2. Analysis of variance after fitting a mixed model to incubation period (IP), latent period (LP), lesion area (LA), and sporulation per $\mathrm{cm}^{2}$ of lesion, with data from two experiments pooled

\begin{tabular}{|c|c|c|c|c|c|c|c|}
\hline Component & Test of fixed effects & df numa & df dena & $F$ value & Probability & Covariance parameterb & Estimate \\
\hline \multirow[t]{3}{*}{ IP } & Clonal lineage (CL) & 1 & 4 & 214.4 & 0.0001 & Isolate $(C L)^{\mathrm{c}}$ & 0.89 \\
\hline & Temperature (Temp) & 3 & 12 & 354.7 & $<0.0001$ & Temp*Isol(CL) ${ }^{c}$ & 3.73 \\
\hline & $\mathrm{CL}^{*} \mathrm{Temp}^{\mathrm{c}}$ & 3 & 12 & 147.6 & $<0.0001$ & Residual & 44.3 \\
\hline \multicolumn{8}{|l|}{ LP } \\
\hline & $\mathrm{CL}$ & 1 & 5.6 & 370.9 & $<0.0001$ & Isolate(CL) & 2.69 \\
\hline & Temp & 3 & 10.6 & 180.8 & $<0.0001$ & Temp*Isol(CL) & 28.70 \\
\hline & CL*Temp & 2 & 10.7 & 134.6 & $<0.0001$ & Residual & 66.56 \\
\hline \multicolumn{8}{|l|}{ LA } \\
\hline & $\mathrm{CL}$ & 1 & 2 & 15.5 & 0.059 & Isolate(CL) & 0.17 \\
\hline & Temp & 3 & 6 & 72.8 & $<0.0001$ & Temp*Isol(CL) & 0.47 \\
\hline & CL*Temp & 3 & 6 & 28.8 & 0.0006 & Residual & 2.81 \\
\hline \multicolumn{8}{|l|}{ Spor/area ${ }^{\mathrm{d}}$} \\
\hline & $\mathrm{CL}$ & 1 & 5.99 & 9.9 & 0.020 & Isolate(CL) & 0.00 \\
\hline & Temp & 3 & 6.05 & 65.4 & $<0.0001$ & Temp*Isol(CL) & 0.007 \\
\hline & CL*Temp & 1 & 5.99 & 8.7 & 0.026 & Residual & 0.096 \\
\hline
\end{tabular}

\footnotetext{
${ }^{a} \mathrm{df}$ num $=$ degrees of freedom of the numerator; $\mathrm{df}$ den = degrees of freedom of the denominator, which were estimated through the Satterthwaite approximation for unbalanced data sets.

${ }^{\mathrm{b}}$ Covariance parameter of random effects.

${ }^{\mathrm{c}} \mathrm{CL} * \mathrm{Temp}=$ clonal lineage $\times$ temperature interaction; Isolate $(\mathrm{CL})=$ isolates nested within clonal lineages; and Temp*Isol $(\mathrm{CL})=$ interaction between temperature and isolates nested within clonal lineages.

${ }^{\mathrm{d}}$ Spor/area $=\log _{10}$ (number of sporangia per $\mathrm{cm}^{2}$ of lesion).
} 

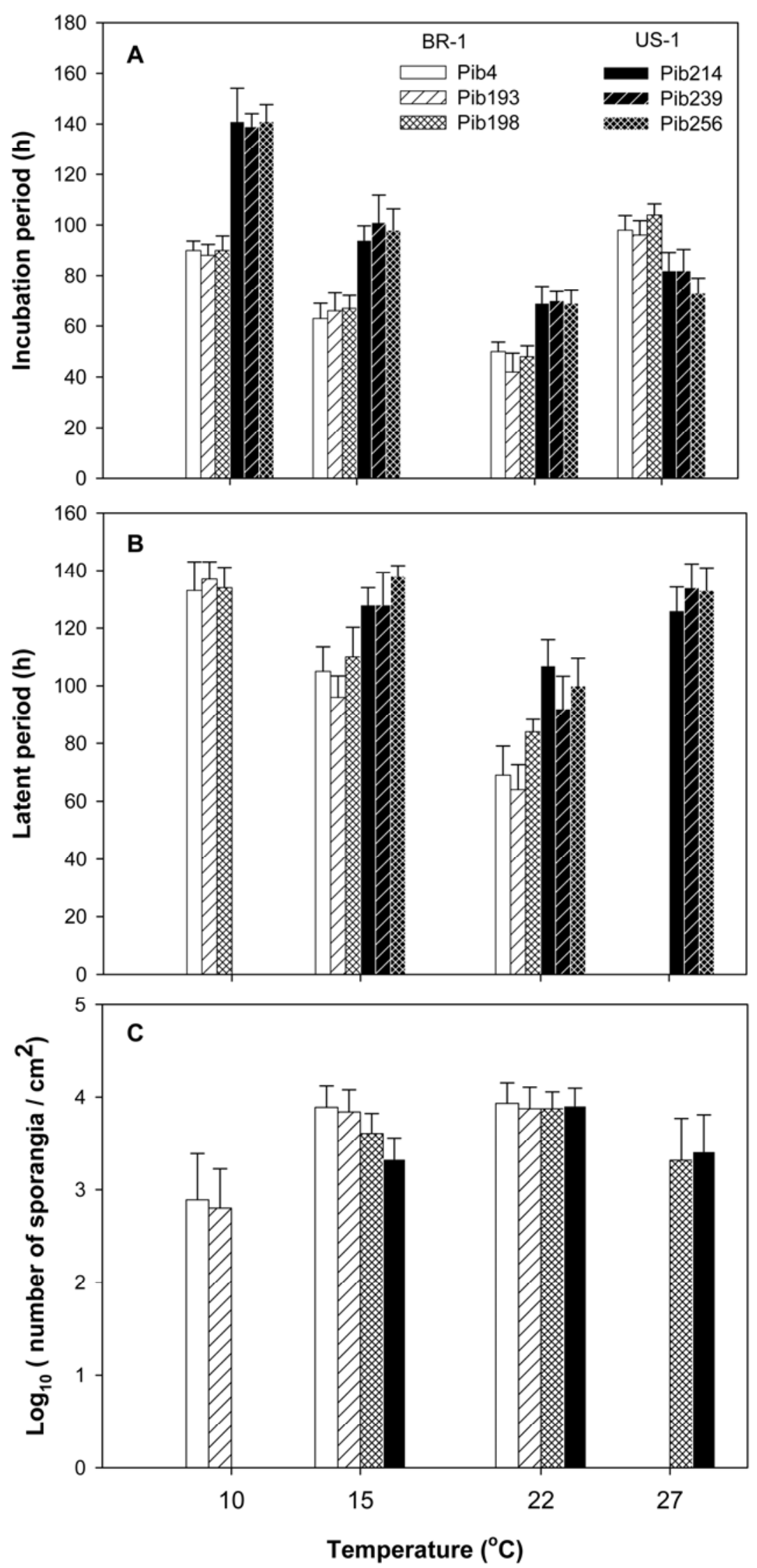

Fig. 3. Incubation period (A), latent period (B), and sporulation per unit of lesion area (C) of isolates of US-1 and BR-1 clonal lineages of Phytophthora infestans in leaflets kept at different temperatures after inoculation, averaged from data of two experiments. Isolates of US-1 or BR-1 were inoculated in tomato or potato leaflets, respectively. Incubation and latent periods were assessed in detached leaflets. Sporulation per unit of lesion area was assessed in whole plants. Error bars represent the standard deviation. for US-1 and BR-1, respectively. Additional experiments in which lesions would be allowed to develop under fluctuating temperature conditions would provide more detailed information on how temperature affects pathogen sporulation.

An interesting question could be raised regarding the effects of temperature on isolates of a lineage when they infect the nonpreferred host. Unfortunately, this effect could not be tested in this study due to differences in aggressiveness between the two lineages when they infect the nonpreferred host. Isolates of US-1 are more aggressive on tomato than on potato, whereas isolates of BR-1 are more aggressive on potato than on tomato (30). In cross-inoculation experiments, the effects of temperature would be confounded with those related to host-specificity.

Populations of $P$. infestans with distinct ecological requirements could have originated from the introduction of genotypes having different requirements and/or from the adaptation of lineages to the climatic conditions where potato and tomato are grown. Recent migrations (gene flow) of $P$. infestans have resulted in the introduction and subsequent distribution of new genotypes in many countries $(8,9)$. These genotypes are distinct from the old US-1 lineage in many epidemiologically important traits such as lower metalaxyl sensitivity (10), higher aggressiveness (17), and differential response to temperature $(18,25)$. Isolates of BR-1 with different ecological requirements might have been introduced to Brazil via seed tubers imported from Europe. The patterns of the Gpi and Pep (100/100) isozymes, typical of BR-1 isolates, are commonly found in European populations of $P$. infestans (27), and in the past there was intensive trade of potato seed tubers with the Netherlands.

Selective adaptation of BR-1 isolates to high altitude climatic conditions, after their introduction in Brazil, is not a plausible hypothesis to explain the differential temperature responses noted in its comparisons with US-1 in this study. Although late blight is known to have occurred in Brazil since 1898 (26), based on all evidence gathered, only A1 mating type isolates, presumably the US-1 lineage, were most likely associated with late blight epidemics until the early 1980s (8) when BR-1 first was detected (2). In contrast, the location of tomato producing areas at lower altitudes, the higher fitness of US-1 on tomato, and the longer time of co-evolution of US- 1 with tomato plants may have contributed to the adaptation of US-1 isolates to higher temperatures. Curiously, sporulation of US-17, a new tomato adapted lineage, inoculated on tomato kept at $28^{\circ} \mathrm{C}$ was almost nil (1), whereas the sporulation of US-1 isolates at $27^{\circ} \mathrm{C}$ was similar to that recorded at the optimum temperature.

The marked effects of temperature in the events of the infection cycle of $P$. infestans 

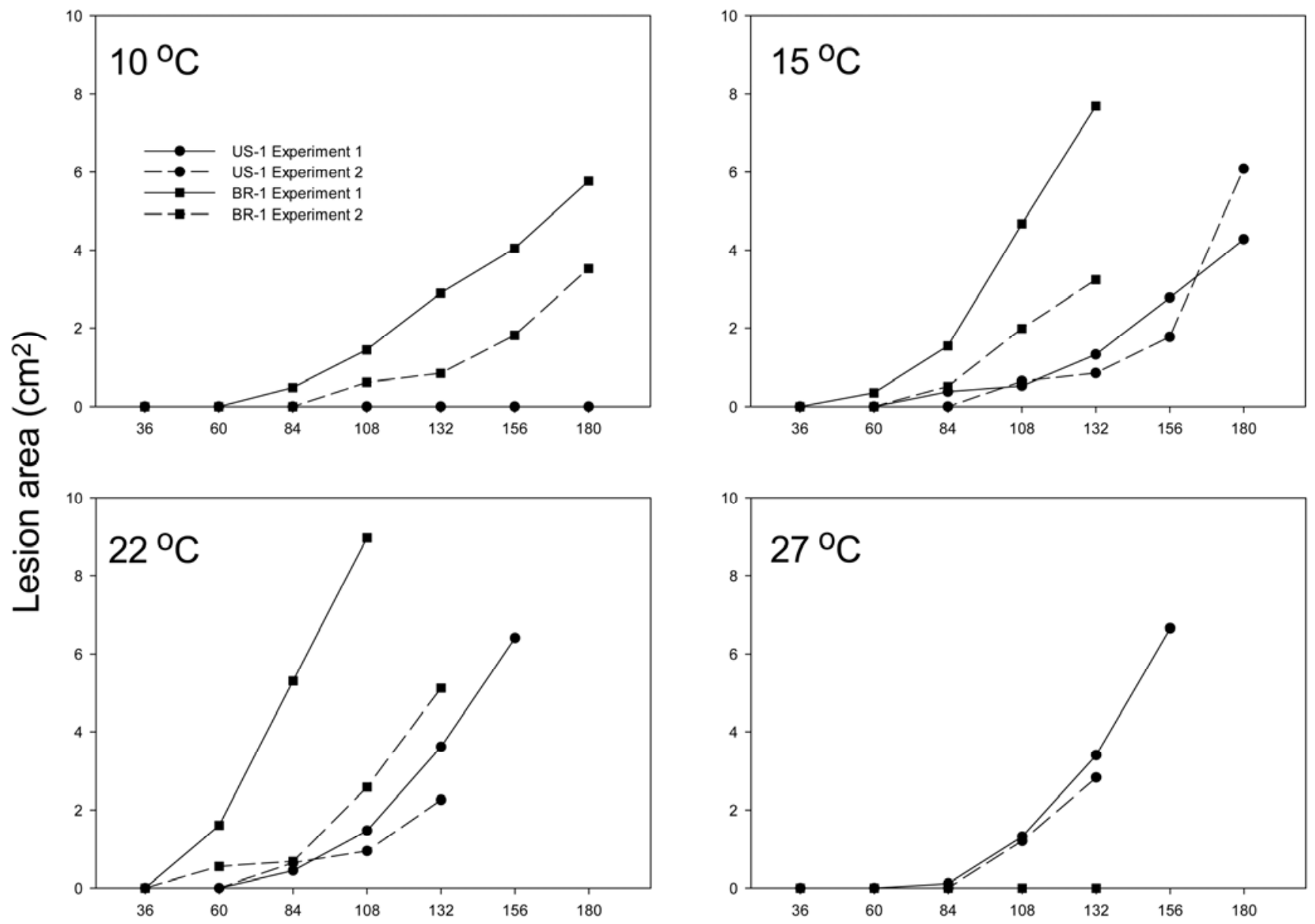

Hours after inoculation

Fig. 4. Lesion area caused by isolates of US-1 and BR-1 clonal lineages of Phytophthora infestans in detached leaflets that were kept at different temperatures and measured at different time intervals, after inoculation, averaged from data of two experiments. Isolates of US-1 or BR-1 were inoculated in tomato or potato leaflets, respectively. Differences in measurement times are due to different leaflet sizes and times at which lesions reached the borders of the leaflets.

lineages in Brazil could affect late blight management, whether epidemics develop on tomato or on potato. The fact that the optimum temperature for US-1 isolates was higher than that for BR-1 isolates helps to explain the frequent outbreaks of severe late blight epidemics on tomato crops during the summer in Brazil. On the other hand, late blight epidemics are likely to be less severe on potato because BR-1, the potato-associated lineage, develops at a slower rate under high temperatures. However, potatoes are grown in areas of high altitude, and temperatures at night can be favorable for infection. Additionally, frequent rains during the summer also favor epidemics. During the winter, temperatures are suitable for late blight epidemics in both hosts, but rains are not common, relative humidity is low, and disease intensity is lower than during the rainy season. The differential responses to ecological variables must be taken into account when implementing disease management tools such as forecast systems and also when using late blight simulation models for the evaluation of control practices.

\section{ACKNOWLEDGMENTS}

We are grateful to FAPEMIG for funding this project and to CAPES for the scholarship (J. M. N. Maziero). Eduardo S. G. Mizubuti and Luiz A. Maffia acknowledge the CNPq fellowships.

\section{LITERATURE CITED}

1. Becktell, M. C., Daughtrey, M. L., and Fry, W. E. 2005. Temperature and leaf wetness requirements for pathogen establishment, incubation period, and sporulation of Phytophthora infestans on Petunia $\times$ hybrida. Plant Dis. 89:975-979.

2. Brommonschenkel, S. H., and Matsuoka, K. 1986. Ocorrência do grupo A2 de Phytophthora infestans em Minas Gerais. (Abstr.) Fitopatol. Bras. 11:327.

3. Caten, C. E., and Jinks, J. L. 1968. Spontaneous variability of single isolates of Phytophthora infestans. I. Cultural Variation. Can. J. Bot. 46:329-348.

4. Crosier, W. 1934. Studies in the biology of Phytophthora infestans (Mont.) De Bary. Cornell Univ. Exp. Stn. Memoir 155.

5. De Weille, G. A. 1964. Forecasting crop infection by the potato blight fungus. Med. Verhand. 82:1-144.

6. Drenth, A., Janssen, E. M., and Govers, F. 1995. Formation and survival of oospores of Phytophthora infestans under natural conditions. Plant Pathol. 44:86-94.

7. Fry, W. E., and Goodwin, S. B. 1997. Resurgence of the Irish Potato Famine fungus. Bio- science 47:363-371

8. Fry, W. E., Goodwin, S. B., Dyer, A. T., Matuszak, J. M., Drenth, A., Tooley, P. W., Sujkowski, L. S., Koh, Y. J., Cohen, B. A., Spielman, L. J., Deahl, K. L., Inglis, D. A., and Sandlan, K. P. 1993. Historical and recent migrations of Phytophthora infestans: Chronology, pathways, and implications. Plant Dis. 77:653-661.

9. Goodwin, S. B., Cohen, B. A., and Fry, W. E. 1994. Panglobal distribution of a single clonal lineage of the Irish potato famine fungus. Proc. Natl. Acad. Sci. USA 91:11591-11595.

10. Goodwin, S. B., Sujkowski, L. S., and Fry, W. E. 1996. Widespread distribution and probable origin of resistance to metalaxyl in clonal genotypes of Phytophthora infestans in the United States and Western Canada. Phytopathology 86:793-800.

11. Guenthner, J. F., Michael, K. C., and Nolte, P. 2001. The economic impact of potato late blight on US growers. Potato Res. 44:121-125.

12. Harrison, J. G. 1992. Effects of the aerial environment on late blight of potato foliage - a review. Plant Pathol. 41:384-416.

13. Harrison, J. G., Barker, H., Lowe, R., and Rees, E. A. 1990. Estimation of amounts of Phytophthora infestans mycelium in leaf tissues by enzyme-linked immunosorbent assay. Plant Pathol. 39:274-277.

14. Harrison, J. G., and Lowe, R. 1989. Effects of humidity and air speed on sporulation of Phytophthora infestans on potato leaves. Plant 
Pathol. 38:585-591.

15. Hartill, W. F. T., Young, K., Allan, D. J., and Henshall, W. R. 1990. Effects of temperature and leaf wetness on the potato late blight. N.Z. J. Crop Hortic. Sci. 18:181-184.

16. Hyre, R. A. 1954. Progress in forecasting late blight of potato and tomato. Plant Dis. Rep. 38:245-253.

17. Kato, M., Mizubuti, E. S., Goodwin, S. B., and Fry, W. E. 1997. Sensitivity to protectant fungicides and pathogenic fitness of clonal lineages of Phytophthora infestans in the United States. Phytopathology 87:973-978.

18. Kirk, W. W. 2003. Tolerance of mycelium of different genotypes of Phytophthora infestans to freezing temperatures for extended periods. Phytopathology 93:1400-1406.

19. Kuehl, R. O. 1994. Statistical Principles of Research Design and Analysis. Duxbury Press, Belmont, CA.

20. Littell, R. C., Milliken, G. A., Stroup, W. W., and Wolfinger, R. D. 1996. SAS System for Mixed Models. SAS Institute, Cary, NC.

21. Mayton, H., Smart, C. D., Moravec, B. C., Mizubuti, E. S. G., Muldoon, A. E., and Fry, W. E. 2000. Oospore survival and pathogenicity of single oospore recombinant progeny from a cross involving US-17 and US-8 geno- types of Phytophthora infestans. Plant Dis. 84:1190-1196.

22. Melhus, I. E. 1915. Germination and infection with the fungus of the late blight of potato (Phytophthora infestans). Agric. Exp. Stn. Univ. WI Res. Bull. 37:1-64.

23. Minogue, K. P., and Fry, W. E. 1981. Effect of temperature, relative humidity, and rehydration rate on germination of dried sporangia of Phytophthora infestans. Phytopathology 71:11811184.

24. Mizubuti, E. S. G. 2001. Requeima ou mela da batata e do tomate. Pages 100-174 in: Doenças causadas por Phytophthora no Brasil. E. D. N. Luz, A. F. Santos, K. Matsuoka, and J. L. Bezerra, eds. Livraria Editora Rural, Campinas.

25. Mizubuti, E. S. G., and Fry, W. E. 1998. Temperature effects on developmental stages of isolates from three clonal lineages of Phytophthora infestans. Phytopathology 88:837843.

26. Potel, H. 1898. As moléstias cryptogamicas da batata ingleza (Solanum tuberosum) e seu tratamento. Bol. Inst. Agron. 10:795-799.

27. Reis, A., Smart, C. D., Fry, W. E., Maffia, L. A., and Mizubuti, E. S. G. 2003. Characterization of isolates of Phytophthora infestans from southern and southeastern Brazil from 1998 to
2000. Plant Dis. 87:896-900.

28. Rotem, J., Cohen, Y., and Putter, J. 1971 Relativity of limiting and optimum inoculum loads, wetting durations, and temperatures for infection by Phytophthora infestans. Phytopathology 61:275-278.

29. Sato, N. 1994. Effect of sporulating temperature on the limit temperature in indirect germination of the sporangia of Phytophthora in festans. Ann. Phytopathol. Soc. Jpn. 60:60-65.

30. Suassuna, N. D., Maffia, L. A., and Mizubuti E. S. G. 2004. Aggressiveness and host specificity of Brazilian isolates of Phytophthora infestans. Plant Pathol. 53:405-413.

31. Tani, S., Kim, K. S., and Judelson, H. S. 2005. A cluster of NIF transcriptional regulators with divergent patterns of spore-specific expression in Phytophthora infestans. Fungal Genet. Biol. 42:42-50.

32. Tani, S., Yatzkan, E., and Judelson, H. S. 2004. Multiple pathways regulate the induction of genes during zoosporogenesis in Phytophthora infestans. Mol. Plant-Microbe Interact. 17:330337.

33. Turkensteen, L. J., Flier, W. G., Wanningen, R., and Mulder, A. 2000. Production, survival and infectivity of oospores of Phytophthora infestans. Plant Pathol. 49:688-696. 